\title{
Circadian rhythms affect bone reconstruction by regulating bone energy metabolism
}

\author{
Beibei Luo ${ }^{1,2,3 \dagger}$, Xin Zhou ${ }^{1,2,3 \dagger}$, Qingming Tang ${ }^{1,2,3}$, Ying Yin ${ }^{1,2,3}$, Guangxia Feng ${ }^{1,2,3}$, Shue $\mathrm{Li}^{1,2,3^{*}}$ and \\ Lili Chen ${ }^{1,2,3^{*}}$ (1)
}

\begin{abstract}
Metabolism is one of the most complex cellular biochemical reactions, providing energy and substances for basic activities such as cell growth and proliferation. Early studies have shown that glucose is an important nutrient in osteoblasts. In addition, amino acid metabolism and fat metabolism also play important roles in bone reconstruction. Mammalian circadian clocks regulate the circadian cycles of various physiological functions. In vertebrates, circadian rhythms are mediated by a set of central clock genes: muscle and brain ARNT like-1 (Bmal1), muscle and brain ARNT like-2 (Bmal2), circadian rhythmic motion output cycle stagnates (Clock), cryptochrome 1 (Cry1), cryptochrome2 (Cry2), period 1 (Per1), period 2 (Per2), period 3 (Per3) and neuronal PAS domain protein 2 (Npas2). Negative feedback loops, controlled at both the transcriptional and posttranslational levels, adjust these clock genes in a diurnal manner. According to the results of studies on circadian transcriptomic studies in several tissues, most rhythmic genes are expressed in a tissue-specific manner and are affected by tissue-specific circadian rhythms. The circadian rhythm regulates several activities, including energy metabolism, feeding time, sleeping, and endocrine and immune functions. It has been reported that the circadian rhythms of mammals are closely related to bone metabolism. In this review, we discuss the regulation of the circadian rhythm/circadian clock gene in osteoblasts/osteoclasts and the energy metabolism of bone, and the relationship between circadian rhythm, bone remodeling, and energy metabolism. We also discuss the therapeutic potential of regulating circadian rhythms or changing energy metabolism on bone development/bone regeneration.
\end{abstract}

Keywords: Circadian rhythm, Circadian clock gene, Osteogenesis, Bone formation, Skeleton formation, Bone, Metabolism, Osteoclast

\section{Introduction}

Most organisms, including humans, have a circadian rhythm that exhibits an endogenous oscillation of $\sim 24 \mathrm{~h}$ and is synchronized with light/dark cycles through morning food consumption or/and light exposure [1]. Circadian rhythm plays a critical role in most

\footnotetext{
*Correspondence: lishue737@hotmail.com; chenlili1030@hust.edu.cn †Beibei Luo and Xin Zhou contributed equally

${ }^{1}$ Department of Stomatology, Union Hospital, Tongji Medical College, Huazhong University of Science and Technology, Wuhan 430022, China Full list of author information is available at the end of the article
}

physiological and behavioral processes in mammals. The suprachiasmatic nucleus ( $\mathrm{SCN})$ is the controlling center of mammalian rhythm oscillation, the rhythm signals of which are influenced by core clock genes, including muscle and brain ARNT like-1 (Bmal1), circadian rhythmic motion output cycle stagnates (clock), cryptochrome (Cry) and period (Per) and orphan nuclear hormone receptors Rora and Rev-erbo [2]. Molecular clocks are known as the mechanisms of circadian rhythms in mammals. They consist mainly of a series of interrelated transcriptiontranslation feedback loops [3]. Temporal information is 
transmitted by the $\mathrm{SCN}$ to peripheral tissue oscillators, producing synchronous circadian rhythms in many bodily processes, including bone metabolism, muscle function, and immune system function [4]. Previous studies have reported that the metabolism of bone and cartilage exhibits circadian rhythms. In an overview of related studies, circadian rhythms can be seen in the expression of the master genes involved in cartilage formation, bone mineral deposition, and bone formation [3, 5-8]. Serum concentrations of some hormones relating to bone metabolism show diurnal variation [9]. For example, serum concentrations of calcium, calcitonin, skeletal alkaline phosphatase, parathyroid hormone C-telopeptide, tartate-resistant acid phosphatase, and osteocalcin show diurnal variation [10-13]. Studies have shown that continuous lighting can lead to a significant decrease in skeletal muscle function and to bone microstructure changes with early osteoporosis characteristics [4]. Studies have shown that chondrocyte-specific Bmall knockout mice exhibit progressive degeneration and damage in knee articular cartilage starting the second month after circadian clock activity of cartilage tissue is disturbed and lasting 3-6 months [14]. Studies have reported that Per and Cry mutant mice showed increased osteoblast activity and bone mass, while Bmal1 knockout mice showed ectopic calcification and abnormal cartilage reendothelialization [4].

Bone, a metabolically active organ, undergoes continuous remodeling due to bone formation by osteoblasts and bone absorption by osteoclasts [15]. In healthy situations, the balance between bone absorption and bone formation is consistent, maintaining bone density and bone strength. Some pathological conditions can affect bone reconstruction, which can lead to bone disease [16]. Bone remodeling requires energy, and growth and repair after bone damage requires more energy [17]. For example, bone healing is the main prognostic factor of oral maxillofacial surgery, and adequate nutrition plays a vital role in fracture repair. Severely malnourished patients show slow wound healing and damage to wound contraction [18]. Studies have shown that oscillations in circadian rhythms lead to rhythmic changes involving physiological processes such as nutrition and metabolism [19]. Moreover, studies have shown that nutritional deficiencies in children are often associated with developmental impairment, which can affect normal bone growth and development. Some defects also directly affect cartilage and bone production [20]. The circadian rhythms of bone functions are regulated by internal or external cues. Feeding and fasting regulate the daily rhythm of the bone turnover marker serum C-telopeptide fragments of collagen type 1 degradation (S-CTX) [21]. The levels of S-CTX are higher in humans during early morning, from 05:00 to 08:00, and lower in the late afternoon, from 12:00 to 16:00. S-CTX have a clear daily rhythm across the $24 \mathrm{~h}$ day under normal feeding conditions, such as the consumption of breakfast, lunch and dinner, while the amplitude of the rhythms is diminished with fasting $[22,23]$. In addition, the generation of this diurnal variation is also observed in intake of glucose, protein, and fat [22]. Circadian disruption can occur with social or environmental factors, such as shift work, may cause dysfunctions of bone and skeletal muscle. In epidemiological studies, the prevalence of metabolic syndrome, bone fractures and osteoporosis are increased in shift workers [24-26]. These findings indicate that the regulation of circadian rhythms in bone by external cues, are important for the maintenance of homeostasis. The interactions involved in bone and energy metabolism are mediated by a variety of nutrients, hormones, and cytokines [27]. Therefore, we explore new ways for the circadian clock to regulate energy metabolism and promote bone development/bone regeneration, and we suggest new strategies for bone reconstruction.

\section{Circadian rhythm in bone}

Currently, due to light pollution at night, passive or active wakefulness late into the night, night shift work and other reasons, the body's circadian rhythm is greatly affected. Studies have shown that circadian rhythm disorders are causes of diminished bone microstructure [28]. Studies have shown that circadian rhythms can affect the development and growth of the mandible; however, to a large extent, circadian dysrhythmia inhibits the growth of the mandible [29]. Continuous light exposure can lead to trabecular bone deterioration and induce a short-term inflammatory state [4]. Epidemiological studies have shown that the incidence of osteoporosis and fractures among shift workers is high [4]. IL-6, an important proinflammatory cytokine expressed in rheumatoid arthritis (OA) [30], mediates osteoclast activation, thus contributing to cartilage and bone breakdown and joint destruction. Previous studies have found that plasma IL-6 levels in rats with collagen-induced arthritis (CIA) were higher at almost every sampling time compared to those in normal rats, and IL-6 expression showed significant circadian rhythms, indicating higher levels during the light phase and lower levels during the dark phase [31]. Recent studies revealed a relationship between circadian rhythm and osteogenesis and osteoclastogenesis. The study found that under the effect of the peripheral nervous system, bone-related genes and bone absorptionrelated genes show periodic expression patterns [32]. Circadian time cues in bone affect osteoblast and osteoclast differentiation, and bone transformation markers exhibit circadian changes [33] (Fig. 1). The expression of 


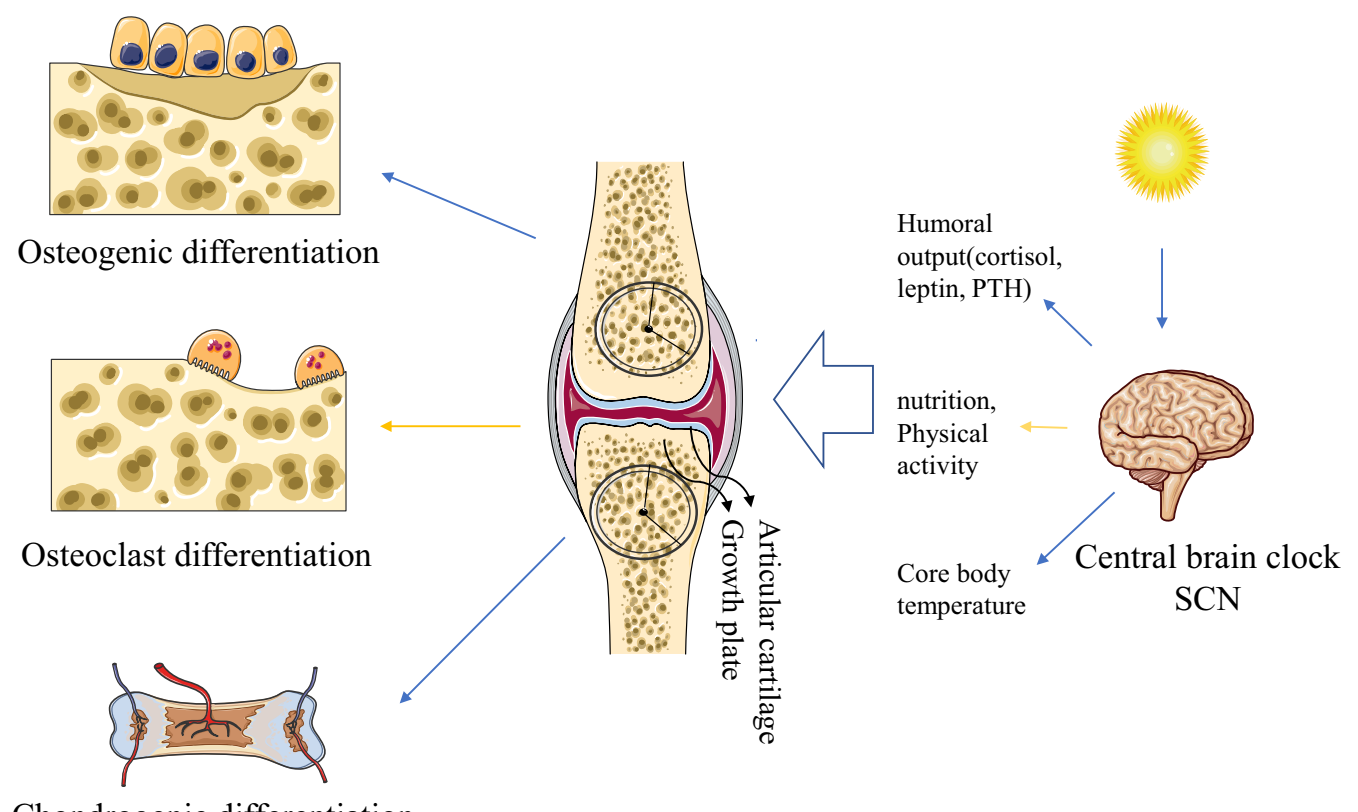

Chondrogenic differentiation

Fig. 1 A pattern diagram of the circadian rhythm regulation of bone

parathyroid hormone (PTH), C-telopeptide of type 1 collage (CTX), calcium, bone specific alkaline phosphatase (BSAP), and calcitonin exhibits circadian rhythm changes [9]. In osteoblasts, $26 \%$ of genes show daytime expression patterns, including bone morphogenetic protein 2 (Bmp2), insulin-like growth factor 1 (Igf1), osteocalcin (Oc, Bglap), and the major osteoblast transcription factor Runt-related transcription factor 2 (Runx2). In humans, circadian rhythms coordinate bone remodeling [34]. The circadian clock is related to bone development and the regulation of homeostasis in bone, molecules associated with osteoblast differentiation are controlled by circadian rhythms, and genes including dentin matrix protein 1(Dmp1), osteopontin(Spp1), bone sialoprotein(Bsp) and osteocalcin(Bglap2) involved in mineral deposition are expressed in circadian rhythm patterns [5, 35-37].

Bones are tissues that continue to be remodeled, and circadian rhythm disorders have a negative impact on bone health. Studies have shown that the circadian clock gene is related to bone formation [38]. Bmal1 plays a key role in regulating bone absorption and bone formation and is the core and irreplaceable component of the circadian rhythm molecular oscillator [39]. The overall absence of Bmal1 in mice led to a decrease in bone mass, which contributed to an increase in bone absorption [40]. Osteoclast-specific Bmal1 knockout mice showed high bone mass-related pelage and additional bone formation compared to wild-type mice because of reduced osteoclast differentiation $[9,40]$. Studies have shown that Bmal1 controls bone absorption by upregulating the expression of nuclear factor of activated T cells, cytoplasmic, calcineurin-dependent 1 (Nfatc1) transcription through its binding to an E-box element located in the Nfatc1 promoter and interacting with members of the steroid receptor coactivator family [41]. Studies have reported that the clock system also exists in osteoblasts [38]. Coculture experiments have shown that osteoblasts with Bmal1 defects exhibit a strong ability to induce the differentiation of osteoclasts, while overexpression of Bmal1/Clock inhibits the expression of calcitriol-induced receptor activator of NF $\mathrm{\kappa B}$ ligand (Rankl), in osteoblasts [40]. Bone homeostasis is affected by circadian rhythms, with bone absorption increased at night compared to daytime. Bone density in the alveolar septum and cortex of the mandible was lower in $B m a l 1^{-/-}$mice than in wild-type mice [42]. Moreover, the $\mathrm{Bmal1}^{-1-}$ animals form short bones and present with osteopenia in the mandibular condyle and long bones [29]. The absence of Bmal1 promotes the differentiation of osteoclasts, inhibits the differentiation of osteoblasts and cartilage cells, and ultimately leads to a decrease in bone mass and bone density. Studies have found that osteogenic differentiation is inhibited in bone marrow stromal cells (BMSCs) and that femoral bone mass is obviously reduced in Bmal1 $^{-1-}$ mice [42]. Bmal1 can also affect myelin cells, regulate the bone mass of the discs between vertebrae and is closely related to the height of these discs [43]. The study revealed a relationship between circadian rhythm 
and the development of mineralized tissue, including osteoclastogenesis and osteogenesis [44, 45]. In addition to Bmal1, Clock, Cry and Per are also the main genes of the molecular clocks. Recent studies also showed that Cry 2 and Per 2 affect multiple mechanisms of adjusting bone volume [32]. Cry2 affects osteoclast activity [46]. In addition, Cry 2 plays an active role in the steady state of the extracellular matrix of cartilage [47]. Per2, a negative regulation factor of circadian clock, is necessary for the maturation of bone tissue. Per2 mutation increases the proliferative ability of osteoblasts [48]. The bone volume was increased in Per and Cry deficient mice [42]. The bone density of mice with mutated Clock was significantly decreased, and the apoptosis rate was increased [38].

Joint cartilage arranged on the surface of long bones is a highly specialized connective tissue. Emerging evidence suggests that circadian rhythm systems play key roles in controlling bone biology and cartilage [13]. Most core clock genes are rhythmically expressed in different types of cartilage, including sword cartilage, facial joint cartilage, growth plates, and rib cartilage $[49,50]$. It has been reported that 619 genes (3.9\% of expressed genes) exhibit circadian rhythm expression patterns in cartilage, including genes that are involved in the stability and survival in cartilage, as well as genes that are potentially important in the pathogenesis of osteoarthritis (OA) [51]. Studies have shown that the most active proliferation stages, which were found by measuring cartilage cell proliferation markers, are in the early morning, causing growth plate expansion to peak at noon [52]. The circadian rhythms of living cartilage can be system-driven, similar to that in other tissues, or by local molecular clocks in cartilage cells [53]. Long-term (22-week) environmental disturbances affect the dark/light cycle and thus the circadian rhythms in mice, generating a condition similar to years of chronic jet lag or shift work, making mouse knees susceptible to OA-like injuries [54]. Bmal1 controls the dynamic balance and integrity of cartilage [6]. In a mouse model of OA, several clock genes in the early stages of cartilage degeneration were disrupted, suggesting a role for circadian rhythms in maintaining a steady state in cartilage. Changing the light and dark cycle of the environment to interfere with circadian rhythms contributed to changes that induce knee osteoarthritis in mice [51].

When it comes to bones, skeletal muscles will be mentioned. Studies have shown that mechanical loads and endocrine factors may be the way for bone and muscles communicating with each other [55]. Studies have shown that skeletal muscle molecular clock are associated with skeletal homeostasis. Loss of Bmal1 solely from adult skeletal muscle (iMSBmall ${ }^{-/-}$) results in severe skeletal system pathology, similar to that observed in the Bmal1 knockout mice. iMSBmal1 ${ }^{-1-}$ have the appearance of misshapen tibia and fibula, flattened tarsals, and increased calcification throughout the rib cage and thoracic spine, which was related to changes in the endocrine/paracrine function of muscle [56]. Therefore, endogenous skeletal muscle molecular clock is a modulator of musculoskeletal health.

\section{Energy metabolism (glucose, amino acid, and fat) in bone}

\section{Glucose metabolism in bone}

In bone systems, glucose is a necessary source of energy for bone and joint cartilage development, growth and maintenance (Fig. 2). During embryo growth and fetal development, bone morphology is particularly important [57]. High blood sugar levels inhibit calcium absorption and bone calcification [58]. Increasing evidence suggests that bone metabolism is closely related to glucose metabolism [59]. Early studies of bone transplantation or isolated osteoblastic cells have shown that glucose is an important nutrient in osteoblasts [60]. Bone absorption has been shown to rely on glycolysis. Studies have shown that osteoclasts fueled by galactose significantly reduced the degradation of type 1 collagen by reducing the rate of glycolysis, forcing cells to rely on oxidative phosphorylation [61]. One study confirmed that glucose intake by osteoblast precursors was the earliest determining factor in osteoblast differentiation and bone formation [62]. Disorder of glucose metabolism changes the maturation process of cartilage cells, suggesting that glucose metabolism plays an indispensable role in the process of bone formation in cartilage. Glucose metabolic disorders are likely not only associated with abnormal cartilage growth but also the force driving these changes [63].Abnormal bone metabolism is a typical phenomenon in diabetic patients [27]. In studies, the bone density and bone strength of the lower limbs were significantly reduced in type 2 diabetes mellitus (T2DM) mice, serum osteocalcin levels were significantly reduced, and serum tartrate-resistant acid phosphatase-5p (TRAP) levels were significantly increased, indicating that bone brittleness in T2DM mice was due to increased bone absorption and decreased bone formation $[15,64]$. Therefore, we can know that glucose metabolism abnormality is very harmful to bone health, energy metabolism is of great significance to bone development and bone regeneration [65]. Studies have shown that bone cells, dysfunction of osteoblasts and collagen crosslinking induced by advanced glycation end products (AGEs) are associated with bone brittleness in diabetes. Increased levels of homocysteine and AGEs in the circulation of diabetic patients directly impair the function of osteoblasts and other bone cells, leading to 


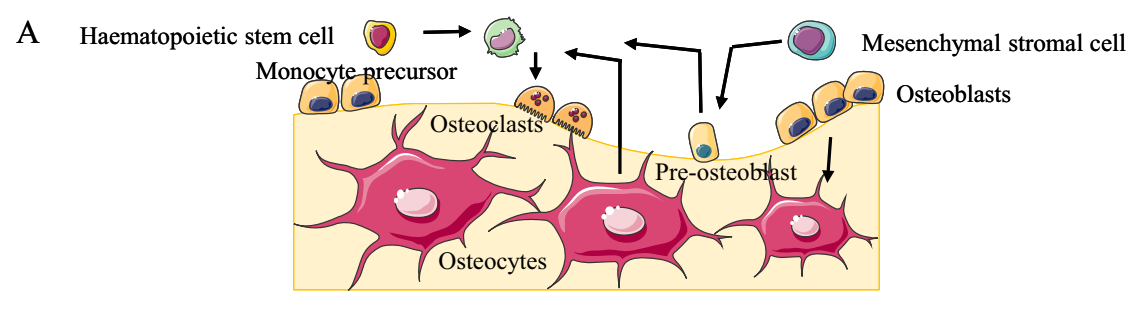

B

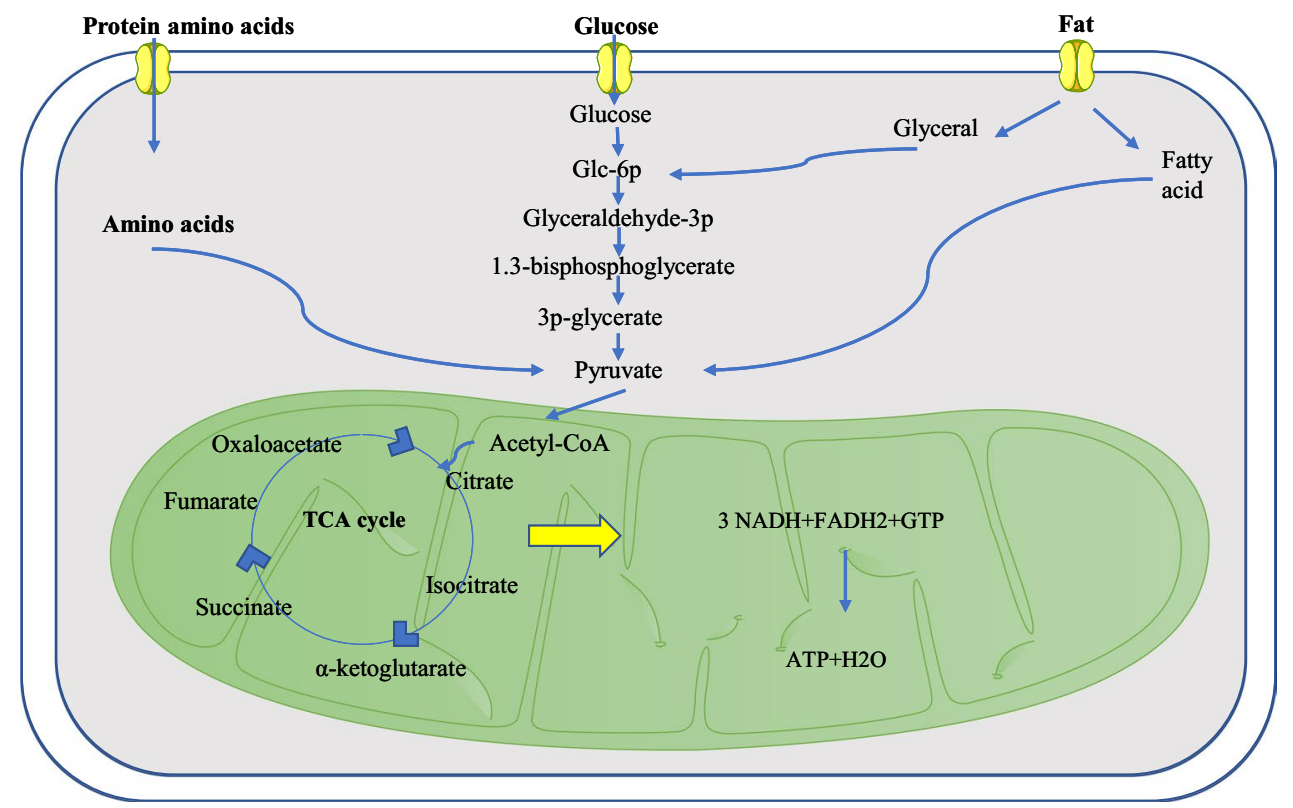

Fig. 2 A Patterns of osteoblast and osteoclast differentiation. B Pattern diagram of energy substrates and intermediate metabolic pathways

reduced bone formation and bone remodeling. When the bone reconstruction process is disrupted, old bone tissue is not renewed and AGE-induced collagen crosslinking is not re-established, leading to a deterioration in bone quality. High blood sugar and AGEs directly or indirectly inhibit bone formation and differentiation of osteoblasts by increasing the level of sclerosis of bone cells and by reducing Rankl expression in osteocytes, reducing the degree of bone reconstruction [59]. It is thought that high sugar levels inhibit the differentiation of osteoblast precursors and osteoblasts [66, 67]. In addition, high concentrations of glucose can lead to excessive production of AGEs and reactive oxygen species (ROS) [64], resulting in less substantial mineralization and abnormal bone formation [68]. Osteocalcin has long been considered a marker of new bone production and is now considered the first hormone produced by bones. Serum osteocalcin levels were found to be associated with new bone formation and the number of osteoblasts [69]. Osteocalcin is a non-collagenous protein secreted by osteoblasts and odontoblasts in the final stages of differentiation and an important factor in mineralization, and its level reflects the degree of bone remodeling [17]. Therefore, bone can be considered closely related to glucose metabolism [59]. Studies have shown that glucose-dependent insulinotropic polypeptide (GIP) and glucagon-like peptide-1 (GLP-1) play important roles in the stable state of glucose metabolism and may be associated with the regulation of bone metabolism [15]. Previous studies have reported that increased glycolysis is involved in osteoblast differentiation caused by Wnt signaling. Studies have shown that Wnt7b increases the expression of glucose transporter 1 (Glut1) and glucose consumption in primary cultures of osteoblasts, while the absence of Glut1 inhibits the in vitro differentiation of osteoblasts. Increased glycolysis mediates bone formation induced by Wnt7b [70]. Studies have revealed a link between glycolysis and osteoblast differentiation [71]. Thyroid side gland-produced hormones and bone-forming Wnt proteins such as Wnt3a and Wnt10b stimulate aerobic glycolysis of osteoblasts [72, 73]. Runt-related transcription factor 2 , a crucial transcription factor for osteoblast differentiation, induces the expression of Glut1 in osteoblasts, while glucose intake inhibits the degradation of Runx 2 to promote 
osteoblast differentiation [62]. Therefore, the study supports the supposition that increased glucose metabolism is an important mechanism for osteoblast differentiation and function [70]. Glucose and fatty acid metabolism are associated with bone anabolism in response to Wnt signaling [74]. Osteoblasts are derived from mesenchymal stem cells (MSCs) and are also ancestors of fat cells. Osteoclasts are derived from hematopoietic stem cells [75]. When glucose metabolism is impaired, peroxisome proliferative activated receptor gamma (PPAR $\gamma$ ) causes an increase in bone transformation by shifting interbone marrow-filled stem cells into fat cells [75]. A recent research shows that a history of night shift work and unhealthy lifestyle can independently or synergistically increase the risk of T2DM [76]. Data show that impairment of glucose metabolism is an emerging risk factor for T2DM, which often occurs in circadian rhythm disorders and sleep deprivation caused by shift work [77]. During shift work, due to circadian rhythm disturbance and sleep deprivation, energy expenditure is affected and energy intake increases, leading to overweight and obesity, which in turn increases the risk of T2DM [78]. Study have shown that the circadian rhythm of bone resorption is regulated and maintained by the feeding and fasting rhythm, although the preventive effect of food intake on bone resorption remains to be studied in depth [79].

\section{Amino acid metabolism in bone}

Studies have shown that amino acid restriction alters bone growth and bone differentiation in rodents [80-83]. Homocysteine, formed by methionine demethylation, is a sulfur-containing amino acid. Hyperhomocysteinemia independent of bone density increases the risk of osteoporotic fractures [84]. In summary, methionine is converted into $S$-adenosylmethionine (SAM), which is a common methyl group donor that contributes to the synthesis of homocysteine [85]. Studies have shown that increases in homocysteine increase the apoptosis rate of osteoblast-derived cells, such as osteocytes [86], osteoblasts [87], and bone marrow stromal cells [88]. Homocysteine can then be re-methylated or vulcanized. After this reaction, glutathione and cysteine are synthesized, which play important roles in antioxidant capacity and protein synthesis, respectively [85]. L-arginine (Arg) and L-lysine (Lys) are essential amino acids in the body and are closely related to osteoporosis and bone and defects [89]. Changes in crosslinking and hydroxy lysine level are related to the mechanical capacity of bones [90, 91]. The content of lysine in collagen plays an indispensable role in the composition of collagen fibred crosslinking. The crosslinking process of bone collagen is essential for bone substation formation and is considered important in bone reconstruction [90] and fracture healing. Bone conversion markers, type I pre-collagen $\mathrm{N}$-end peptides and type I collagen $\mathrm{C}$-end peptides, such as provide sensitive indicators of bone formation and bone absorption, respectively [92]. Metabolomics-based studies have reported correlations found with amino acid and bone health assessments [93-95]. In a cross-sectional study of women aged 18-79 years, studies linked arginine, alanine, glutamate and proline intake to higher bone density in the forearms and spine [96]. In addition to the potential impact on collagen synthesis, arginine also promotes the production of bone cells. Tryptophan metabolism is thought to affect the activity of osteoclasts $[89,97,98]$. Mechanistically, surface molecules on T cells (CTLA4) combined with $C D 80 / 86$ can activate the enzyme indoleamine 2,3-dioxygenase (IDO) in osteoclast precursors, thereby degrading tryptophan and promoting apoptosis [99].

\section{Fat metabolism in bone}

There is a close link between bone and fat metabolism [100]. The bone trabecular area is where the active bone remodeling process takes place. The positioning of bone fat in the bone trabecular area suggests that bone marrow fat may be involved in bone reconstruction, possibly by providing energy for hematopoietic and bone marrow filling [101]. Fat cells play key roles in maintaining energy balance, storing energy in the form of lipids and releasing fatty acids when metabolic signals or energy is low [102]. Previous studies have reported that adipose tissue is related to bone metabolism. Organ fat cells not only store energy but also secrete a variety of bioactive factors called fat factors [59]. Studies have shown that there is an inverse relationship between bone mass and fat mass in bones. The increase in fat content in bone was found to be negatively related to bone mass in ageing and negatively related to the decrease in bone acquisition during growth [103-105]. The peroxisome proliferator-activated receptor 2 (PPAR-2) subtype is activated with natural (fatty acids and ecological steroids) or artificial (TZD) ligands to induce bone marrow mesenchymal stem cells to differentiate into fat cells at the expense of bone-forming-cell development, resulting in bone mass reduction [106-108]. Obese patients usually exhibit higher bone mineral density than people of normal weight [109-111]. Endocrine activity in fat cells leads to the production of fat factors, through which leptin and lipids regulate the calorie intake and insulin sensitivity of the outer tissue, respectively; these fat factors are also produced in bones [101]. The main function of leptin is to regulate the amount of fat stored in the body, which regulates hunger and energy consumption [112]. Leptin was the first hormone found in adipose 
tissue more than 20 years ago, and since its discovery, evidence has accumulated to support the hypothesis that adipose tissue is an endocrine organ associated with regulating energy metabolism [113]. Studies have shown that adiponectin inhibits the formation of fat cells, stimulates the phenotype acquisition and cell proliferation of osteoblasts, and inhibits the production of osteoclasts in vitro [114]. Animal studies have shown that leptin increases bone density, bone mineral content and bone formation $[115,116]$. Studies have shown that Wnt, PTH and IGF signaling stimulates glycolysis and glutamine to induce metabolism while increasing bone accumulation [117]. Leptin, a fat cell-derived hormone, regulates bone metabolism through the sensory nervous system and the central nervous system [118]. Fat levels have been found to be associated with bone density and fracture risk [119]. Studies in animals have shown that fat-muscle-bone relationships may be associated with circulating osteocalcin, a bone cell- and osteoblast-specific peptide [120].

\section{The circadian clock regulates energy metabolism}

The circadian rhythm regulates several activities, including energy metabolism, feeding time, sleep, and endocrine and immune function [147]. In recent years, a great number of studies have emphasized that the circadian clock system is closely related to the maintenance of energy metabolism [148-153] (Table 1). The circadian clock has been shown to regulate the daily fluctuations of certain human metabolites, such as glucose [154] amino acids and fatty acids, regardless of the fasting/eating cycle [155]. These metabolites control and regulate physiological processes at the cell, organ and biological levels, integrating signals received from outside the cell

Table 1 Metabolic phenotypes of clock disorders in mice

\begin{tabular}{|c|c|c|}
\hline Mouse/experiment/mutation & Phenotype/mechanism & References \\
\hline Chronic jet lag (6 h advance/week) & Weight gain & {$[121]$} \\
\hline SCN lesion & Loss of behavioral and molecular rhythms, obesity, hyperphagy & {$[122]$} \\
\hline Light exposure at night & Metabolic and behavioral phase shifts, weight gain & {$[123,124]$} \\
\hline Per3 knockout & Increased fat mass & {$[125]$} \\
\hline Liver Bmal1 knockout & Hypoglycemia during fasting period & {$[126]$} \\
\hline Pancreas Bmal1 knockout & Hypoinsulinemia & {$[127]$} \\
\hline Cry1/2 double knockout & Loss of behavioral rhythms, hyperinsulinemia & {$[126,128]$} \\
\hline global Bmal1 knockout & cataract, sarcopenia, arthropathy, and so on & {$[129]$} \\
\hline Clock $\triangle 19$ mice and the Clock/Npas2 double knockout & spontaneously calcifying tendons & {$[130]$} \\
\hline Cry & $\begin{array}{l}\text { CRY also inhibits the transmission of signals downstream of glucagon recep- } \\
\text { tors, thus affecting the production of glycosomes at specific time }\end{array}$ & {$[131]$} \\
\hline REV-ERB and HNF6 & REV-ERB and HNF6 interact to regulate lipid metabolism & {$[132]$} \\
\hline Npas $2^{-/-}$mice & $\begin{array}{l}\text { Lack nap-type rest periods during the activity Period and cannot be adjusted } \\
\text { properly when the eating Time suddenly changes }\end{array}$ & {$[133]$} \\
\hline Global Per1/2 knockout & Reduced total hepatic triglycerides lever & {$[134]$} \\
\hline Clock, Bmal1, Cry2 & $\begin{array}{l}\text { Single nucleotide polymorphisms in Cry2, Bmall and Clock can alter an indi- } \\
\text { vidual's risk of type } 2 \text { diabetes, abnormal blood lipids }\end{array}$ & {$[135-137]$} \\
\hline Clock mutant, Bmal1 ${ }^{-/-}$and Rev-erba ${ }^{-/-}$mice & $\begin{array}{l}\text { Hyperlipidemic } \\
\text { Age-related skeletal muscle loss } \\
\text { Fiber-type shift } \\
\text { Impaired muscle regeneration }\end{array}$ & {$[129,138,139]$} \\
\hline $\begin{array}{l}\text { liver-specific Bmall or } \\
\text { Rev-erba deletion }\end{array}$ & $\begin{array}{l}\text { Levels of triglycerides, cholesterol and free fatty acids increased during circula- } \\
\text { tion }\end{array}$ & {$[140,141]$} \\
\hline Global Clock $\triangle 19$ mutation & Decreased glucose tolerance. Reduced plasma free fatty acids & {$[142]$} \\
\hline Clock mutant & $\begin{array}{l}\text { lack the circadian pattern of enterocyte gene expression and lipid absorption } \\
\text { The disruption of myofiber architecture } \\
\text { Reduction in muscle strength. Reduction in mitochondria }\end{array}$ & {$[143]$} \\
\hline Muscle-specific Bmall knockout & $\begin{array}{l}\text { Insulin resistance and glucose intolerance } \\
\text { Impaired insulin stimulated glucose uptake } \\
\text { Increased muscle mass and size } \\
\text { Decreased muscle strength }\end{array}$ & {$[144]$} \\
\hline Per2 knockout or Per2 mutant & No change in muscle mass and lower exercise tolerance & {$[8]$} \\
\hline Rev-erbaa knockout & $\begin{array}{l}\text { Disruption of myofiber architecture } \\
\text { Lower exercise capacity } \\
\text { Slight fiber-type shift }\end{array}$ & {$[145,146]$} \\
\hline
\end{tabular}


and generated during normal metabolism with different control mechanisms to accommodate possible local disturbances while maintaining circadian rhythms, optimizing energy distribution in most cases [147]. Transcription studies have shown that many genes involved in biosynthetic and metabolic processes are rhythmic and that their expression changes throughout the physiological cycle [156-159]. A 48-h assessment of human plasma samples revealed that most metabolites (109 clock metabolites of 171 metabolites) oscillated during a full 24-h waking/sleep cycle [160]. Thus, for humans, most circulating metabolites exhibit rhythmic circadian oscillations under normal physiological conditions [161].

Rhythm disorders lead to a decline in quality of life and are involved in metabolic syndrome, the development of obesity and neuro-psychiatric disorders [147]. Work associated with circadian rhythm disorders is shift work and air travel across meridians (jet lag). Shift work can disrupt central and outer biological clocks synchronization, further disrupting glucose metabolism by reducing insulin sensitivity, independent of sleep loss [162, 163]. Under dynamic equilibrium conditions, the clock rhythm is the driving force of biological metabolism [164]. Glucose metabolism is a complex physiological process. In humans, daily changes in insulin sensitivity and insulin secretion within $24 \mathrm{~h}$ were shown to fluctuate according to significant daily rhythms [165]. Studies have shown that the circadian clock system may maintain a dynamic balance of sugar metabolism by regulating the activity of key enzymes in glucose metabolism [166]. Pax6 mutant mice $\left(\right.$ Pax $\left.^{\text {Leca2 }}\right)$ have disorganized melanin-positive intrinsically photosensitive retinal ganglionic cells in eyelike structures and show loss of circadian rhythm. In vivo studies have shown that $\operatorname{Pax}^{\text {Leca2 }}$ mice had reduced liver glucose production and reduced hepatic function, possibly due to a loss of rhythm in the metabolic process [167]. In mice, the absence of liver-specific Bmal1 led to reduced liver glucose production and increased glucose tolerance [168]. Therefore, as observed in the Pax$6^{\text {Leca2 }}$ mice, the loss of circadian rhythms may result in inhibition of liver function [167]. In addition, the loss of Bmal1 and Clock may lead to increased insulin sensitivity, which may be due to interruption to the core clock composition in living individuals $[165,168,169]$. At the cellular level, mitochondrial redox reactions [170], phosphate oxide [171, 172], and antioxidant defences [173] are regulated not only by circadian rhythms but also by feedback signaling to the core clock. Studies by Ashley et al. have shown that models of multifunctional amino acid-substituted cells obtained from patients with Snyder-Robinson syndrome indicate that mitochondrial dysfunction is a potential cause of bone defects [174]. Studies by $\mathrm{T}$ aira Wada et al. have shown that Bmal1 regulation of skeletal muscle metabolism provides more insight into the link between obesity/diabetes and the circadian clock system in energy metabolism [175]. Studies by Ik Dong Yoo et al. have shown that overexpression of Clock and Bmal1 significantly inhibited aerobic sulfation and lactic acid production by reducing the protein expression levels of hexokinase 1 (HK1) and lactate dehydrogenase A (LDHA) [176]. Redox stress is an important metabolic regulation factor [177]. Circadian rhythm disorders alter a variety of proteins that are known to regulate glucose stability and/or energy metabolism and are involved in changes in metabolic physiology. The findings of Christopher M. Depner et al. demonstrated that studying the circadian clock, behavioral food intake-fasting/waking-sleep cycles, and the interactions between these processes help in identifying mechanisms that can lead to metabolic disorders and regulate the 24-h pattern in human plasma protein expression [178]. Many of the rate-limiting steps in metabolic pathways associated with metabolic diseases are regulated by circadian rhythms [179], further suggesting circadian rhythm disorder roles in metabolic disorders. Eun Roh et al. found that clock genes mediate the regulation of neuropeptide $\mathrm{Y}$ (NPY) and agouti-related protein (AGRP) transcription and suggested a new mechanism explaining the association between clock genes and system metabolic regulation. Overexpressed nicotinamide adenine dinucleotide (NAD) may help obese mice restore day and night fluctuations in retarded metabolic behaviors by enhancing the interaction of clock genes with NPY and AGRP [180]. CREB, hepatocyte specific (CREBH) regulates the acute stage response and energy balance of the liver under stress conditions and is regulated by the circadian clock [170]. Circadian rhythms are produced through a network of clock-controlled genes at the level of gene transcription that form an automatically regulated feedback loop [181]. The Clock/Bmal1 heterogenic dimer drives the circadian rhythm expression of many other transcription factors, enhancing and extending other circadian rhythm- adjusted functions. Liver nuclear targets or transcriptional regulators may be direct links between circadian rhythms and metabolic pathways [175]. Ze Zheng et al. showed that CREBH activation is regulated by circadian oscillations in the liver and that CREBH is an organ-specific circadian rhythm regulator of lipid metabolism. The dysfunction of CREBH led to impaired rhythms of triglyceride and fatty acid expression. The study found that the core circadian oscillator Bmal1 regulated the activation/cracking of CREBH via AKTGSK3 $\beta$ signaling (Fig. 3). Core circadian oscillations regulate CREBH activity: (1) Core circadian oscillation Bmal1 regulates CREBH protein hydrolytic activation; (2) the output circadian rhythm regulator DBP or E4BP4 


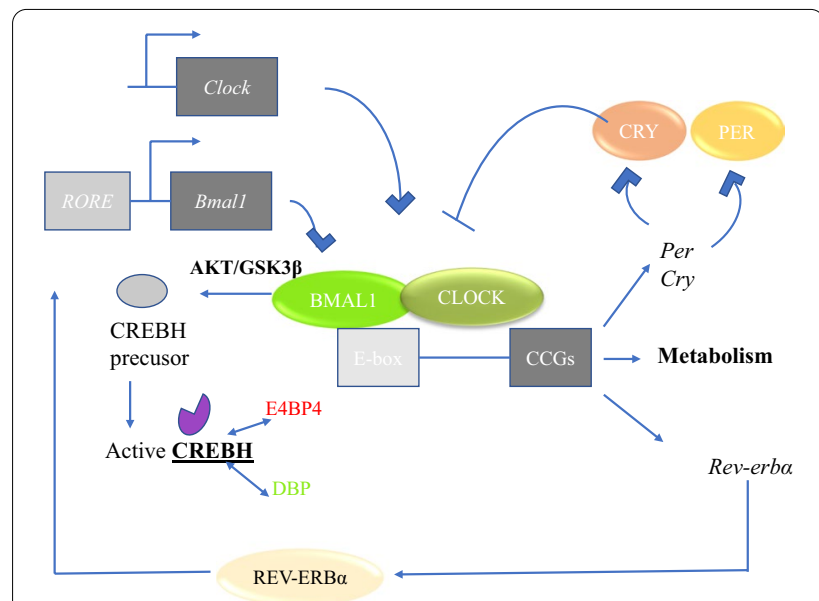

Fig. 3 The core molecular circadian clock is present in all mammalian cells and consists of a single unit of positive (CLOCK and BMAL1) and negative (CRY, PER, and REV-ERB alpha). Molecular clocks regulate the expression of hundreds of clock control genes (CCGs), including metabolic media. BMAL1 regulates the activation/cracking of CREBH via AKT-GSK3 $\beta$ signaling. Core circadian oscillations regulate $C R E B H$ activity: (1) The core circadian oscillation BMAL1 protein regulates CREBH protein hydrolytic activation; (2) the output circadian rhythm regulator $\mathrm{DBP}$ or $\mathrm{E} 4 \mathrm{BP} 4$ interacts with the activated $\mathrm{CREBH}$ protein to inhibit or synergize with CREBH activity

interacts with the activated CREBH protein to inhibit or synergize with CREBH activity [182]. In a two-year study, Leticia Goni and others found a significant interaction between the melatonin receptor 1B (MTNR1B) gene and dietary fat intake, affecting changes in obesity level, body composition and fat distribution [183]. The role of circadian rhythm systems in controlling energy balance has long been thought to be associated with the regulation of body fat [184]. Circadian Clock-mutant mice showed a decrease in transcript expression of specific hypothalamic peptides encoded to participate in energy balance [183]. Mice fed a high-fat diet with a mutation in circadian clock developed obesity at a young age, as well as metabolic and endocrine abnormalities consistent with metabolic syndrome [129]. Studies have shown that the transcription factor co-activation by PGC-1a is an important function of the liver and muscle circadian clock and is the main regulator of mitochondrial biological occurrence and energy metabolism. There is a regulatory circuit between the clock machinery and metabolism [161]. The fat cell-derived hormone leptin plays a vital role in metabolic control by reducing food intake and increasing energy consumption. Studies by Alisa Boucsein et al. show that leptin sensitivity is controlled within a 24-h rhythm, in which diet-induced obesity (DIO) is disrupted, causing impaired energy metabolic regulation [185]. Feeney et al. reported a novel physiological function of $\mathrm{Mg}^{2+}$ in cell circadian rhythm regulation.
They observed rhythmic changes in the concentration of magnesium ions in cells that regulate cell timing and energy balance. $\mathrm{Mg}^{2+}$ is an important rate-limiting factor for many metabolic effects; therefore, we think that the differential expression level of PRL2 (a member of the phosphatase family expressed in regenerating liver) can regulate the concentration of $\mathrm{Mg}^{2+}$ in cells to balance the energy needs of cells. The results of noriko Uetani et al. suggest a model in which the daily oscillations caused by PRL2 expression produce rhythmic $\mathrm{Mg}^{2+}$ currents, which lead to an appropriate daily metabolic cycle [186].

\section{Circadian rhythm and bone energy metabolism}

Circadian rhythms regulate activities such as eating time, sleep, energy metabolism, and endocrine-related case conditions under the action of a circadian clock located in the central nervous system and peripheral cells [187]. The study also found an interesting phenomenon in which methotrexate raises the important cell circadian rhythm gene, leading to the apoptosis of sliding membrane fibroblasts. The link between circadian rhythms of the disease and time therapy for rheumatoid arthritis is promising $[188,189]$. Bone reconstruction is a continuous process of bone formation by osteoblasts and bone absorption by osteoclasts to maintain balance [190]. The development and differentiation of these two different cells are strictly regulated by many endogenous substances, including growth factors, hormones, cytokines and neurotransmitters [191]. Glucose is the main source of energy for most mammalian cells. Glucose is metabolized in the cytoplasm through glycolysis. Glycolysis produces many intermediate metabolites that are essential for various biosynthetic pathways. Pyruvate, the final product of glycolysis, can be converted into lactic acid or further oxidized in the tricarboxylic cycle [60]. The intermediates of tricarboxylic acid are usually extracted from the cycle through a process called quenching to support biosynthesis, redox regulation and the apparent genetic regulation of lipids and amino acids [192-194]. There is growing evidence to show that glycolysis in osteoblast cells is directly stimulated by a variety of anabolic signaling pathways in bone [60]. Parathyroid hormone signaling was previously shown to stimulate lactic acid production and glucose consumption in bone implants before it was clinically used to promote bone formation in osteoporotic patients [195]. The activity of osteoblasts and osteoclasts is regulated by a series of signaling pathways, including parathyroid hormone signaling pathways, and more importantly, parathyroid hormones are expressed via circadian rhythms [190]. In addition to hormones, other factors that regulate bone reconstruction are also rhythmically expressed, such as calcium, 
osteocalcin, C-telopeptide, bone alkaline phosphatase, and calcitonin [10-12]. So we can make a bold guess that circadian rhythms can affect bone building by regulating the energy metabolism of the bone.

\section{Summary and outlook}

The circadian clock is associated with bone development and the regulation of bone homeostasis; most molecules involved in osteoblast differentiation are controlled by circadian rhythms, and most genes associated with mineral deposition appear in circadian rhythm patterns [5, 35-37]. In bone systems, glucose is a necessary source of energy for bone and joint cartilage development, growth and maintenance. During embryo growth and fetal development, bone morphology is particularly important [57]. At the same time, amino acid metabolism and fat metabolism also play important roles in bone differentiation $[117,196]$. Therefore, energy metabolism is of great significance for bone development/bone regeneration. In recent years, many studies have emphasized that the circadian clock system is closely related to the maintenance of energy metabolism [148-153]. These reports show that circadian rhythms can regulate bone activity, which is important for bone development/bone regeneration, and that the circadian clock regulates energy metabolism. However, the relationship between circadian rhythms and bone energy metabolism has not been well articulated, and further evidence is needed to advance the understanding of the interaction between the circadian clock and bone energy metabolism.

\footnotetext{
Abbreviations

SCN: Suprachiasmatic nucleus; Bmal1: Muscle and brain ARNT like-1; Clock: Circadian rhythmic motion output cycle stagnates; Cry: Cryptochrome; Per: Period; Npas2: Neuronal PAS domain protein 2; S-CTX: Serum C-telopeptide fragments of collagen type 1 degradation; OA: Rheumatoid arthritis; CIA: Collagen-induced arthritis; PTH: Parathyroid hormone; CTX: C-telopeptide of type 1 collage; BSAP: Bone specific alkaline phosphatase; Runx2: Runt-related transcriptional factor 2; Dmp1: Dentin matrix protein 1; Bsp: Bone sialoprotein; Igf1: Insulin-like growth factor 1; Oc: Osteocalcin; Bmp2: Bone morphogenetic protein 2; NF: Nuclear factor; Nfatc1: Nuclear factor of activated T cells; Cytoplasmic: Calcineurin-dependent 1; RANKL: Receptor activator of NF-KB ligand; BMSCs: Bone marrow stromal cells; SMH: Skeletal mandibular hypoplasia; AGEs: Advanced glycation end products; ROS: Reactive oxygen species; OCN: Osteocalcin; GIP: Glucose-dependent insulinotropic polypeptide; GLP-1: Glucagon-like peptide 1; Glut1: Glucose transporter 1; MSC: Mesenchymal stem cells; PPARY: Peroxisome proliferative activated receptor; SAM: S-Adenosylmethionine; Arg: L-arginine; Lys: L-lysine; IDO: Indoleamine 2,3-dioxygenase; ER: Endo-plasmic reticulum; HK1: Hexokinase 1; LDHA: Lactate dehydrogenase A; NPY: Neuropeptide Y; AgRP: Agouti-related protein; NAD: Nicotinamide adenine dinucleotide; HFD: Feeding high-fat diet; MTNR1B: Melatonin receptor 1B; TRAP: Tartrate-resistant acid phosphatase5p;T2DM: Type 2 diabetes mellitus; DM: Diabetes mellitus; DIO: Diet-induced obesity; CREBH: CREB, hepatocyte specific; PRL: Phosphatase of regenerating liver; PPAR-2: Peroxisome proliferator-activated receptor.
}

Acknowledgements

Not applicable.

\section{Authors' contributions}

BL and XZ performed the original draft preparation, revision, created the tables and figures, and were the major contributors in writing the manuscript. QT, YY and GF made suggestions to the writing of the manuscript and revisions to tables and figures. LC and SL participated in conceptualization and methodology. LC supervised the work. All authors read and approved the final manuscript.

\section{Funding}

This work was supported by the National Science Foundation for Distinguished Young Scholars of China (31725011, to Lili Chen), the National Natural Science Fund (82001026, to Xin Zhou).

Availability of data and materials

Not applicable.

\section{Declarations}

Ethics approval and consent to participate

Not applicable,

\section{Consent for publication}

Not applicable.

\section{Competing interests}

The authors declare that they have no competing interests.

\section{Author details}

${ }^{1}$ Department of Stomatology, Union Hospital, Tongji Medical College, Huazhong University of Science and Technology, Wuhan 430022, China. ${ }^{2}$ School of Stomatology, Tongji Medical College, Huazhong University of Science and Technology, Wuhan 430030, China. ${ }^{3}$ Hubei Province Key Laboratory of Oral and Maxillofacial Development and Regeneration, Wuhan 430022, China.

Received: 19 June 2021 Accepted: 2 September 2021

Published online: 27 September 2021

\section{References}

1. Husse J, Eichele G, Oster H. Synchronization of the mammalian circadian timing system: light can control peripheral clocks independently of the SCN clock. BioEssays. 2015;37(10):1119-28. https://doi. org/10.1002/bies.201500026.

2. Yoshida $\mathrm{K}$, et al. TNF-alpha induces expression of the circadian clock gene Bmal1 via dual calcium-dependent pathways in rheumatoid synovial cells. Biochem Biophys Res Commun. 2018;495(2):1675-80. https://doi.org/10.1016/j.bbrc.2017.12.015.

3. Li G, et al. Muscle-bone crosstalk and potential therapies for sarcoosteoporosis. J Cell Biochem. 2019;120(9):14262-73. https://doi.org/ 10.1002/jcb.28946.

4. Lucassen EA, et al. Environmental 24-hr cycles are essential for health Curr Biol. 2016;26(14):1843-53. https://doi.org/10.1016/j.cub.2016.05. 038.

5. McElderry JD, et al. Tracking circadian rhythms of bone mineral deposition in murine calvarial organ cultures. J Bone Miner Res. 2013;28(8):1846-54. https://doi.org/10.1002/jbmr.1924.

6. Takarada T, et al. Bone resorption is regulated by circadian clock in osteoblasts. J Bone Miner Res. 2017;32(4):872-81. https://doi.org/10. 1002/jbmr.3053.

7. Gafni Y, et al. Circadian rhythm of osteocalcin in the maxillomandibular complex. J Dent Res. 2009;88(1):45-50. https://doi.org/10.1177/ 0022034508328012

8. Maronde $\mathrm{E}$, et al. The clock genes period 2 and cryptochrome 2 differentially balance bone formation. PLoS ONE. 2010;5(7): e11527. https://doi.org/10.1371/journal.pone.0011527.

9. Dudek M, Meng Q. Running on time: the role of circadian clocks in the musculoskeletal system. Biochem J. 2014;463(1):1-8. https://doi. org/10.1042/BJ20140700. 
10. Shao P, Ohtsuka-Isoya M, Shinoda H. Circadian rhythms in serum bone markers and their relation to the effect of etidronate in rats. Chronobiol Int. 2009;20(2):325-36.

11. Greenspan $S L$, et al. Diurnal variation of bone mineral turnover in elderly men and women. Calcif Tissue Int. 1997;60(5):419-23. https:// doi.org/10.1081/cbi-120019343.

12. Srivastava AK, et al. Circadian and longitudinal variation of serum C-telopeptide, osteocalcin, and skeletal alkaline phosphatase in $\mathrm{C} 3 \mathrm{H}$ / HeJ mice. Bone. 2001;29(4):361-7. https://doi.org/10.1016/s87563282(01)00581-6.

13. Yang N, Meng Q. Circadian clocks in articular cartilage and bone. J Biol Rhythms. 2016;31(5):415-27. https://doi.org/10.1177/07487 30416662748.

14. Davidson ENB, van Caam APM, van der Kraan PM. Osteoarthritis year in review 2016: biology. Osteoarthritis Cartlage. 2017;25(2):175-80. https://doi.org/10.1016/j.joca.2016.09.024.

15. Kanda J, et al. Effects of the linagliptin, dipeptidyl peptidase-4 inhibitor, on bone fragility induced by type 2 diabetes mellitus in obese mice. Drug Discov Ther. 2020;14(5):218-25. https://doi.org/10.5582/ ddt.2020.03073.

16. Heilmeier U, Patsch J. Diabetes and bone. Semin Musculoskelet Radiol. 2016;20(03):300-4. https://doi.org/10.1055/s-0036-1592366.

17. Duskova $M$, et al. Are there sex differences in the reaction of undercarboxylated osteocalcin to hypoglycemia? Physiol Res. 2020;69(Suppl 2):S315-20. https://doi.org/10.33549/physiolres. 934520.

18. Giridhar VU. Role of nutrition in oral and maxillofacial surgery patients. Natl J Maxillofac Surg. 2021;7(1):3-9. https://doi.org/10 4103/0975-5950.196146.

19. Cagampang FR, Bruce KD. The role of the circadian clock system in nutrition and metabolism. Br J Nutr. 2012;108(3):381-92. https://doi. org/10.1017/S0007114512002139.

20. Prentice A, Schoenmakers I, et al. Nutrition and bone growth and development. Proc Nutr Soc. 2006;65(4):348-60. https://doi.org/10. 1017/s0029665106005192.

21. Gertz BJ, et al. Application of a new serum assay for type I collagen cross-linked N-telopeptides: assessment of diurnal changes in bone turnover with and without alendronate treatment. Calcif Tissue Int. 1998;63(2):102-6. https://doi.org/10.1007/s002239900497.

22. Bjarnason $\mathrm{NH}$, et al. Mechanism of circadian variation in bone resorption. Bone. 2002;30(1):307-13. https://doi.org/10.1016/S8756 3282(01)00662-7.

23. Qvist $P$, et al. Circadian variation in the serum concentration of C-terminal telopeptide of type I collagen (serum CTx): effects of gender, age, menopausal status, posture, daylight, serum cortisol, and fasting. Bone. 2002;31(1):57-61. https://doi.org/10.1016/s87563282(02)00791-3.

24. Feskanich D, Hankinson SE, Schernhammer ES. Nightshift work and fracture risk: the Nurses' health study. Osteoporos Int. 2009;20(4):53742. https://doi.org/10.1007/s00198-008-0729-5.

25. Pietroiusti $A$, et al. Incidence of metabolic syndrome among night-shift healthcare workers. Occup Environ Med. 2009;67(1):54-7. https://doi. org/10.1136/oem.2009.046797.

26. Quevedo I, Zuniga AM. Low bone mineral density in rotating-shift workers. J Clin Densitom. 2010;13(4):467-9. https://doi.org/10.1016/j. jocd.2010.07.004

27. Booth SL, et al. The role of osteocalcin in human glucose metabolism: marker or mediator? Nat Rev Endocrinol. 2013;9(1):43-55. https://doi. org/10.1038/nrendo.2012.201

28. Copinschi G, Caufriez A. Sleep and hormonal changes in aging Endocrinol Metab Clin North Am. 2013;42(2):371-89. https://doi.org/10. 1016/j.ecl.2013.02.009

29. Zhou X, et al. BMAL1 deficiency promotes skeletal mandibular hypoplasia via OPG downregulation. Cell Prolif. 2018;51(5): e12470. https:// doi.org/10.1111/cpr.12470.

30. Mclnnes IB, Liew FY. Cytokine networks - towards new therapies for rheumatoid arthritis. Nat Clin Pract Rheumatol. 2005;1(1):31-9. https:// doi.org/10.1038/ncprheum0020.

31. Wang $X$, et al. Role of methotrexate chronotherapy in collagen-induced rheumatoid arthritis in rats. Z Rheumatol. 2018;77(3):249-55. https:// doi.org/10.1007/s00393-016-0236-6.
32. Qin X, et al. The circadian expression of osteogenic factors in periodontal tissue loading mechanical force: new concepts of the personalized orthodontic care. EPMA J. 2019;10(1):13-20. https://doi.org/10.1007/ s13167-019-0161-2.

33. Rogers TS, et al. Rest-activity circadian rhythms and bone mineral density in elderly men. Bone Rep. 2017;7:156-63. https://doi.org/10.1016/j. bnor.2017.11.001.

34. Smith SS, et al. MicroRNA-433 dampens glucocorticoid receptor signaling, impacting circadian rhythm and osteoblastic gene expression. J Biol Chem. 2016;291(41):21717-28. https://doi.org/10.1074/jbc.m116. 737890.

35. Guntur AR, et al. An essential role for the circadian-regulated gene nocturnin in osteogenesis: the importance of local timekeeping in skeletal homeostasis. Ann N Y Acad Sci. 2011;37(12):58-63. https://doi.org/10. 1111/j.1749-6632.2011.06213.x.

36. Zvonic S, et al. Circadian oscillation of gene expression in murine calvarial bone. J Bone Miner Res. 2007;22(3):357-65. https://doi.org/10.1359/ jbmr.061114.

37. HeY, et al. Roles of brain and muscle ARNT-like 1 and Wnt antagonist Dkk1 during osteogenesis of bone marrow stromal cells. Cell Prolif. 2013;46(6):644-53. https://doi.org/10.1111/cpr.12075.

38. Yuan $\mathrm{G}$, et al. The circadian GeneClock regulates bone formation via PDIA3. J Bone Miner Res. 2017;32(4):861-71. https://doi.org/10.1002/ jbmr.3046.

39. Bunger MK, et al. Mop3 is an essential component of the master circadian pacemaker in mammals. Cell. 2000;103(7):1009-17. https://doi. org/10.1016/s0092-8674(00)00205-1.

40. Egstrand S, Olgaard K, Lewin E. Circadian rhythms of mineral metabolism in chronic kidney disease-mineral bone disorder. Curr Opin Nephrol Hypertens. 2020;29(4):367-77. https://doi.org/10.1097/MNH. 0000000000000611

41. Xu C, et al. Circadian clock regulates bone resorption in mice. J Bone Miner Res. 2016;31(7):1344-55. https://doi.org/10.1002/jbmr.2803.

42. Samsa WE, et al. Deficiency of circadian clock protein BMAL1 in mice results in a low bone mass phenotype. Bone. 2016;84:194-203. https:// doi.org/10.1016/j.bone.2016.01.006

43. Suyama K, et al. Circadian factors BMAL1 and RORalpha control HIF-1alpha transcriptional activity in nucleus pulposus cells: implications in maintenance of intervertebral disc health. Oncotarget. 2016:7(17):23056-71. https://doi.org/10.18632/oncotarget.8521.

44. Komoto $S$, et al. Comparison of $\beta$-adrenergic and glucocorticoid signaling on clock gene and osteoblast-related gene expressions in human osteoblast. Chronobiol Int. 2012;29(1):66-74. https://doi.org/10.3109/ 07420528.2011 .636496

45. Fujihara Y, et al. Glucocorticoids mediate circadian timing in peripheral osteoclasts resulting in the circadian expression rhythm of osteoclastrelated genes. Bone. 2014;61:1-9. https://doi.org/10.1016/j.bone.2013. 12.026.

46. Al-Waeli $\mathrm{H}$, et al. Chronotherapy of non-steroidal anti-inflammatory drugs may enhance postoperative recovery. Sci Rep. 2020;10(1):468. https://doi.org/10.1038/s41598-019-57215-y.

47. Bekki H, et al. Suppression of circadian clock protein cryptochrome 2 promotes osteoarthritis. Osteoarthr Cartil. 2020;28(7):966-76. https:// doi.org/10.1016/j.joca.2020.04.004.

48. Abe T, et al. The period circadian clock 2 gene responds to glucocorticoids and regulates osteogenic capacity. Regen Ther. 2019;11:199-206. https://doi.org/10.1016/j.reth.2019.07.006.

49. Dudek M, et al. The chondrocyte clock gene Bmal1 controls cartilage homeostasis and integrity. J Clin Invest. 2016;126(1):365-76. https://doi. org/10.1172/JCl82755.

50. Gossan N, et al. The circadian clock in murine chondrocytes regulates genes controlling key aspects of cartilage homeostasis. Arthritis Rheum. 2013;65(9):2334-45. https://doi.org/10.1002/art.38035.

51. Akagi $R$, et al. Dysregulated circadian rhythm pathway in human osteoarthritis: NR1D1 and BMAL1 suppression alters TGF-beta signaling in chondrocytes. Osteoarthr Cartil. 2017;25(6):943-51. https://doi.org/ 10.1016/j.joca.2016.11.007.

52. Stevenson $\mathrm{S}$, et al. Is longitudinal bone growth influenced by diurnal variation in the mitotic activity of chondrocytes of the growth plate? J Orthop Res. 1990;8(1):132-5. https://doi.org/10.1002/jor.1100080117. 
53. Kornmann B, et al. Regulation of circadian gene expression in liver by systemic signals and hepatocyte oscillators. Cold Spring Harb Symp Quant Biol. 2007;72(1):319-30. https://doi.org/10.1101/sqb.2007.72.041.

54. Kc R, et al. Environmental disruption of circadian rhythm predisposes mice to osteoarthritis-like changes in knee joint. J Cell Physiol. 2015;230(9):2174-83. https://doi.org/10.1002/jcp.24946.

55. Dankbar B, et al. Myostatin is a direct regulator of osteoclast differentiation and its inhibition reduces inflammatory joint destruction in mice. Nat Med. 2015;21(9):1085-90. https://doi.org/10.1038/nm.3917.

56. Schroder EA, et al. Intrinsic muscle clock is necessary for musculoskeletal health. J Physiol. 2015;593(24):5387-404. https://doi.org/10.1113/ JP271436.

57. Mobasheri A. Glucose: an energy currency and structural precursor in articular cartilage and bone with emerging roles as an extracellular signaling molecule and metabolic regulator. Front Endocrinol (Lausanne). 2012;3:153. https://doi.org/10.3389/fendo.2012.00153.

58. Balint $E$, et al. Glucose-induced inhibition of in vitro bone mineralization. Bone. 2001;28(1):21-8. https://doi.org/10.1016/s8756-3282(00) 00426-9.

59. Kanazawa I. Interaction between bone and glucose metabolism [Review]. Endocr J. 2017;64(11):1043-53. https://doi.org/10.1507/endoc rj.EJ17-0323.

60. Karner CM, Long F. Glucose metabolism in bone. Bone. 2018;2018(115):2-7. https://doi.org/10.1016/j.bone.2017.08008.

61. Lemma S, et al. Energy metabolism in osteoclast formation and activity. Int J Biochem Cell Biol. 2016;2016(79):168-80. https://doi.org/10.1016/j. biocel.2016.08034.

62. Wei J, et al. Glucose uptake and Runx2 synergize to orchestrate osteoblast differentiation and bone formation. Cell. 2015;161(7):1576-91. https://doi.org/10.1016/j.cell.2015.05.029.

63. Hollander JM, Zeng $L$. The emerging role of glucose metabolism in cartilage development. Curr Osteoporos Rep. 2019;17(2):59-69. https:// doi.org/10.1007/s11914-019-00506-0.

64. Skubis-Sikora A, et al. Osteogenesis of adipose-derived stem cells from patients with glucose metabolism disorders. Mol Med. 2020;26(1):67. https://doi.org/10.1186/s10020-020-00192-0.

65. Evert $A B$, et al. Nutrition therapy recommendations for the management of adults with diabetes. Diabetes Care. 2013;37(Supplement_1):S120-43. https://doi.org/10.2337/dc14-S120.

66. Jiao H, Xiao E, Graves DT. Diabetes and its effect on bone and fracture healing. Curr Osteoporos Rep. 2015;13(5):327-35. https://doi.org/10. 1007/s11914-015-0286-8.

67. Li H, Jiang L, Dai L. High glucose potentiates collagen synthesis and bone morphogenetic protein-2-induced early osteoblast gene expression in rat spinal ligament cells. Endocrinology. 2010;151(1):63-74. https://doi.org/10.1210/en.2009-0833.

68. Ehnert $\mathrm{S}$, et al. Factors circulating in the blood of type 2 diabetes mellitus patients affect osteoblast maturation-description of a nove in vitro model. Exp Cell Res. 2015;332(2):247-58. https://doi.org/10. 1016/j.yexcr.2014.12.011.

69. Brown JP, et al. Serum bone Gla-protein: a specific marker for bone formation in postmenopausal osteoporosis. Lancet. 1984;1 (8386):1091-3. https://doi.org/10.1016/s0140-6736(84)92506-6.

70. Chen $\mathrm{H}$, et al. Increased glycolysis mediates Wnt7b-induced bone formation. FASEB J. 2019;33(7):7810-21. https://doi.org/10.1096/ff.20190 0201RR.

71. Esen E, Long F. Aerobic glycolysis in osteoblasts. Curr Osteoporos Rep. 2014;12(4):433-8. https://doi.org/10.1007/s11914-014-0235-y.

72. Esen $\mathrm{E}$, et al. PTH promotes bone anabolism by stimulating aerobic glycolysis via IGF signaling. J Bone Miner Res. 2015;30(11):2137-2137. https://doi.org/10.1002/jbmr.2714.

73. Esen $\mathrm{E}$, et al. WNT-LRP5 signaling induces Warburg effect through mTORC2 activation during osteoblast differentiation. Cell Metab. 2013:17(5):745-55. https://doi.org/10.1016/j.cmet.2013.03.017.

74. Karner CM, Long F. Wnt signaling and cellular metabolism in osteoblasts. Cell Mol Life Sci. 2017;74(9):1649-57. https://doi.org/10.1007/ s00018-016-2425-5.

75. Aung $M$, et al. The future of Metformin in the prevention of diabetesrelated osteoporosis. Curēus (Palo Alto, CA). 2020;12(9):e10412-e10412. https://doi.org/10.7759/cureus.10412.
76. Shan Z, et al. Rotating night shift work and adherence to unhealthy lifestyle in predicting risk of type 2 diabetes: results from two large US cohorts of female nurses. BMJ. 2018;2018:k4641. https://doi.org/10. 1136/bmj.k4641.

77. Stenvers DJ, et al. Circadian clocks and insulin resistance. Nat Rev Endocrinol. 2019;15(2):75-89. https://doi.org/10.1038/ s41574-018-0122-1(2018).

78. Broussard JL, Van Cauter E. Disturbances of sleep and circadian rhythms. Curr Opin Endocrinol Diabetes Obes. 2016;23(5):353-9. https://doi.org/ 10.1097/med.0000000000000276(2016)

79. McHill AW, Wright KP. Role of sleep and circadian disruption on energy expenditure and in metabolic predisposition to human obesity and metabolic disease. Obes Rev. 2017;18:15-24. https://doi.org/10.1111/ obr.12503(2017)

80. Huang TH, et al. A methionine-restricted diet and endurance exercise decrease bone mass and extrinsic strength but increase intrinsic strength in growing male rats. J Nutr. 2014;144(5):621-30. https://doi. org/10.3945/jn.113.187922.

81. Ouattara A, et al. Methionine restriction alters bone morphology and affects osteoblast differentiation. Bone Rep. 2016;5:33-42. https://doi. org/10.1016/j.bonr.2016.02.002.

82. Ables GP, et al. Methionine-restricted $\mathrm{C} 57 \mathrm{BL} / 6 \mathrm{~J}$ mice are resistant to diet-induced obesity and insulin resistance but have low bone density. PLoS ONE. 2012;7(12): e51357. https://doi.org/10.1371/journal.pone. 0051357.

83. Plummer J, et al. Methionine-restricted diet increases miRNAs that can target RUNX2 expression and alters bone structure in young mice. J Cell Biochem. 2017;118(1):31-42. https://doi.org/10.1002/jcb.25604.

84. van Meurs JB, et al. Homocysteine levels and the risk of osteoporotic fracture. N Engl J Med. 2004;350(20):2033-41. https://doi.org/10.1056/ NEJMoa032546.

85. Ables GP, Johnson JE. Pleiotropic responses to methionine restriction. Exp Gerontol. 2017;94(8):83-8. https://doi.org/10.1016/j.exger.2017.01. 012.

86. Takeno A, et al. Activation of AMP-activated protein kinase protects against homocysteine-induced apoptosis of osteocytic MLO-Y4 cells by regulating the expressions of NADPH oxidase 1 (Nox1) and Nox2. Bone. 2015;77:135-41. https://doi.org/10.1016/j.bone.2015.04.025.

87. Park S, et al. Involvement of endoplasmic reticulum stress in homocysteine-induced apoptosis of osteoblastic cells. J Bone Miner Metab. 2012;30(4):474-84. https://doi.org/10.1007/s00774-011-0346-9.

88. Kim DJ, et al. Homocysteine enhances apoptosis in human bone marrow stromal cells. Bone. 2006;39(3):582-90. https://doi.org/10.1016/j. bone.2006.03.004.

89. Fini $\mathrm{M}$, et al. Effect of L-lysine and L-arginine on primary osteoblast cultures from normal and osteopenic rats. Biomed Pharmacother. 2001;55(4):213-20.

90. Oxlund $\mathrm{H}$, et al. Reduced concentrations of collagen cross-links are associated with reduced strength of bone. Bone. 1995;17(4):S365-71. https://doi.org/10.1016/8756-3282(95)00328-b.

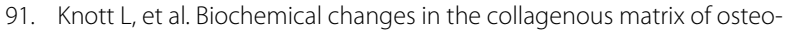
porotic avian bone. Biochem J. 1995;310(3):1045-51. https://doi.org/10. 1042/bj3101045.

92. Bellissimo MP, et al. Metabolomic associations with serum bone turnover markers. Nutrients. 2020;12(10):3161. https://doi.org/10.3390/nu121 03161.

93. Zhao Q, et al. Metabolomic profiles associated with bone mineral density in US Caucasian women. Nutr Metab (Lond). 2018;15:57. https://doi. org/10.1186/s12986-018-0296-5.

94. Miyamoto T, et al. Metabolomics-based profiles predictive of low bone mass in menopausal women. Bone Rep. 2018;9:11-8. https://doi.org/ 10.1016/j.bonr.2018.06004.

95. You YS, et al. Association between the metabolome and low bone mineral density in Taiwanese women determined by (1)H NMR spectroscopy. J Bone Miner Res. 2014;29(1):212-22. https://doi.org/10.1002/ jbmr.2018.

96. Jennings $A$, et al. Amino acid intakes are associated with bone mineral density and prevalence of low bone mass in women: evidence from discordant monozygotic twins. J Bone Miner Res. 2016;31(2):326-35. https://doi.org/10.1002/jbmr.2703. 
97. Huh JE, et al. Arginine enhances osteoblastogenesis and inhibits adipogenesis through the regulation of Wnt and NFATc signaling in human mesenchymal stem cells. Int J Mol Sci. 2014;15(7):13010-29. https://doi. org/10.3390/ijms150713010.

98. Torricelli P, et al. L-arginine and L-lysine stimulation on cultured human osteoblasts. Biomed Pharmacother. 2002;56(10):492-7. https://doi.org/ 10.1016/s0753-3322(02)00287-1.

99. Bozec A, et al. T cell costimulation molecules CD80/86 inhibit osteoclast differentiation by inducing the IDO/tryptophan pathway. Sci Transl Med. 2014;6(235):23560-23560. https://doi.org/10.1126/scitranslmed. 3007764.

100. Ukita M, et al. Sclerostin enhances adipocyte differentiation in 3T3-L1 cells. J Cell Biochem. 2016;17(6):1419-28. https://doi.org/10.1002/jcb. 25432.

101. Lecka-Czernik B. Marrow fat metabolism is linked to the systemic energy metabolism. Bone. 2012;50(2):534-9. https://doi.org/10.1016/j. bone.2011.06.032.

102. Ali AT, et al. Adipocyte and adipogenesis. Eur J Cell Biol. 2013;92(67):229-36. https://doi.org/10.1016/j.ejcb.2013.06.001.

103. Griffith JF, et al. Vertebral bone mineral density, marrow perfusion, and fat content in healthy men and men with osteoporosis: dynamic contrast-enhanced MR imaging and MR spectroscopy. Radiology. 2005;236(3):945-51. https://doi.org/10.1148/radiol.2363041425.

104. Shen W, et al. MRI-measured bone marrow adipose tissue is inversely related to DXA-measured bone mineral in Caucasian women. Osteoporos Int. 2007;18(5):641-7. https://doi.org/10.1007/s00198-006-0285-9.

105. Wren TAL, et al. Bone marrow fat is inversely related to cortical bone in young and old subjects. J Clin Endocrinol Metab. 2011;96(3):782-6. https://doi.org/10.1210/jc.2010-1922.

106. Lazarenko OP, et al. Rosiglitazone induces decreases in bone mass and strength that are reminiscent of aged bone. Endocrinology. 2007;148(6):2669-80. https://doi.org/10.1210/en.2006-1587.

107. Lecka-Czernik B, Suva LJ. Resolving the two "Bony" faces of PPARgamma. PPAR Res. 2006;2006:1-9. https://doi.org/10.1155/PPAR/2006/ 27489.

108. Muruganandan S, Roman AA, Sinal CJ. Adipocyte differentiation of bone marrow-derived mesenchymal stem cells: cross talk with the osteoblastogenic program. Cell Mol Life Sci. 2009;66(2):236-53. https:// doi.org/10.1007/s00018-008-8429-z.

109. Riggs BL, Khosla S, Melton LJ. A unitary model for involutional osteoporosis: estrogen deficiency causes both type I and type II osteoporosis in postmenopausal women and contributes to bone loss in aging men. J Bone Miner Res. 1998;13(5):763-73. https://doi.org/10.1359/jbmr.1998. 13.5.763.

110. Felson DT, et al. Effects of weight and body mass index on bone mineral density in men and women: the Framingham study. J Bone Miner Res. 1993;8(5):567-73. https://doi.org/10.1002/jbmr.5650080507.

111. Tremollieres FA, Pouilles JM, Ribot C. Vertebral postmenopausal bone loss is reduced in overweight women: a longitudinal study in 155 early postmenopausal women. J Clin Endocrinol Metab. 1993;77(3):683-6. https://doi.org/10.1210/jcem.77.3.8370689.

112. Shao J, et al. Bone regulates glucose metabolism as an endocrine organ through osteocalcin. Int J Endocrinol. 2015;2015: 967673. https://doi. org/10.1155/2015/967673.

113. Friedman J. 20 years of leptin: Leptin at 20: an overview. J Endocrinol. 2014;223(1):T1-8. https://doi.org/10.1530/JOE-14-0405.

114. Yokota T, et al. Paracrine regulation of fat cell formation in bone marrow cultures via adiponectin and prostaglandins. J Clin Investig. 2002;109(10):1303-10. https://doi.org/10.1172/JCl14506.

115. Hamrick MW, et al. Leptin treatment induces loss of bone marrow adipocytes and increases bone formation in leptin-deficient ob/ob mice. J Bone Miner Res. 2005;20(6):994-1001. https://doi.org/10.1359/JBMR. 050103.

116. Hamrick MW. Leptin, bone mass, and the thrifty phenotype. J Bone Miner Res. 2004;19(10):1607-11. https://doi.org/10.1359/JBMR.040712.

117. Lee $W$, et al. Energy metabolism of the osteoblast: implications for osteoporosis. Endocr Rev. 2017;38(3):255-66. https://doi.org/10.1210/er. 2017-00064.

118. Hinoi E. Pivotal role of skeletal tissues in the regulation mechanisms for physiological functions mediated by multiple organ networks.
Yakugaku Zasshi. 2012;132(6):721-5. https://doi.org/10.1248/yakushi. 132.721.

119. Gonnelli S, et al. Divergent effects of obesity on fragility fractures. Clin Interv Aging. 2014;9:1629. https://doi.org/10.2147/CIA.S64625.

120. Kanazawa I. Osteocalcin as a hormone regulating glucose metabolism. World J Diabetes. 2015;6(18):1345-54. https://doi.org/10.4239/ wjd.v6.i18.1345.

121. Oike $\mathrm{H}$, et al. Time-fixed feeding prevents obesity induced by chronic advances of light/dark cycles in mouse models of jet-lag/shift work. Biochem Biophys Res Commun. 2015;465(3):556-61. https://doi.org/ 10.1016/j.bbrc.2015.08.059.

122. Coomans CP, et al. The suprachiasmatic nucleus controls circadian energy metabolism and hepatic insulin sensitivity. Diabetes. 2013;62(4):1102-8. https://doi.org/10.2337/db12-0507.

123. Borniger JC, et al. Acute dim light at night increases body mass, alters metabolism, and shifts core body temperature circadian rhythms. Chronobiol Int. 2014;31(8):917-25. https://doi.org/10.3109/07420528. 2014.926911

124. Fonken LK, et al. Dim light at night exaggerates weight gain and inflammation associated with a high-fat diet in male mice. Endocrinology. 2013;154(10):3817-25. https://doi.org/10.1210/en.2013-1121.

125. Costa MJ, et al. Circadian rhythm gene period 3 is an inhibitor of the adipocyte cell fate. J Biol Chem. 2011;286(11):9063-70. https://doi. org/10.1074/jbc.M110.164558.

126. Kolbe I, Oster H. Chronodisruption, metabolic homeostasis, and the regulation of inflammation in adipose tissues. Yale J Biol Med. 2019:92(2):317-25

127. Lee J, et al. Bmal1 and $\beta$-cell clock are required for adaptation to circadian disruption, and their loss of function leads to oxidative stress-induced $\beta$-cell failure in mice. Mol Cell Biol. 2013;33(11):232738. https://doi.org/10.1128/MCB.01421-12.

128. Horst GTJV, et al. Mammalian Cry1 and Cry2 are essential for maintenance of circadian rhythms. Nature. 1999;398(6728):627-30. https:// doi.org/10.1038/19323.

129. Turek FW. Obesity and metabolic syndrome in circadian clock mutant mice. Science. 2005;308(5724):1043-5. https://doi.org/10.1126/scien ce. 1108750 .

130. Yeung CC et al. Gremlin-2 is a BMP antagonist that is regulated by the circadian clock. Sci Rep. 2015;4(1). https://doi.org/10.1038/srep0 5183.

131. Zhang EE, et al. Cryptochrome mediates circadian regulation of CAMP signaling and hepatic gluconeogenesis. Nat Med. 2010;16(10):1152-6. https://doi.org/10.1038/nm.2214.

132. Zhang Y, et al. HNF6 and Rev-erba integrate hepatic lipid metabolism by overlapping and distinct transcriptional mechanisms. Genes Dev. 2016;30(14):1636-44. https://doi.org/10.1101/gad.281972.116.

133. Dudley CA. Altered patterns of sleep and behavioral adaptability in NPAS2-deficient mice. Science. 2003;301(5631):379-83. https://doi. org/10.1126/science.1082795.

134. Kumar Jha P, Challet E, Kalsbeek A. Circadian rhythms in glucose and lipid metabolism in nocturnal and diurnal mammals. Mol Cell Endocrinol. 2015;418:74-88. https://doi.org/10.1016/j.mce.2015.01.024.

135. Monteleone P, Maj M. The circadian basis of mood disorders: recent developments and treatment implications. Eur Neuropsychopharmacol. 2008;18(10):701-11. https://doi.org/10.1016/j.euroneuro.2008.06. 007.

136. Sookoian S, Pirola CJ. Non-alcoholic fatty liver disease is strongly associated with carotid atherosclerosis: a systematic review. J Hepatol. 2008;49(4):600-7. https://doi.org/10.1016/j.jhep.2008.06.012.

137. Garaulet M, Madrid JA. Chronobiological aspects of nutrition, metabolic syndrome and obesity 4 . Adv Drug Deliv Rev. 2010;62(910):967-78. https://doi.org/10.1016/j.addr.2010.05.005.

138. Dyar KA, et al. The calcineurin-NFAT pathway controls activitydependent circadian gene expression in slow skeletal muscle. Mol Metab. 2015;4(11):823-33. https://doi.org/10.1016/j.molmet.2015.09. 004.

139. Kondratov RV. Early aging and age-related pathologies in mice deficient in BMAL1, the core componentof the circadian clock. Genes Dev. 2006;20(14):1868-73. https://doi.org/10.1101/gad.1432206. 
140. Cho H, et al. Regulation of circadian behaviour and metabolism by REVERB- $a$ and REV-ERB-ß. Nature. 2012;485(7396):123-7. https://doi.org/10. 1038/nature11048.

141. Jacobi $D$, et al. Hepatic Bmal1 regulates rhythmic mitochondrial dynamics and promotes metabolic fitness. Cell Metab. 2015;22(4):709-20. https://doi.org/10.1016/j.cmet.2015.08006.

142. Kennaway DJ, et al. Metabolic homeostasis in mice with disruptedClock gene expression in peripheral tissues. Am J Physiol Regul Integr Comparat Physiol. 2007;293(4):R1528-37. https://doi.org/10.1152/ajpre gu.000182007.

143. Andrews JL, et al. CLOCK and BMAL1 regulate MyoD and are necessary for maintenance of skeletal muscle phenotype and function. Proc Natl Acad Sci. 2010;107(44):19090-5. https://doi.org/10.1073/pnas.10145 23107.

144. Aoyama S, Shibata S. The role of circadian rhythms in muscular and osseous physiology and their regulation by nutrition and exercise. Front Neurosci. 2017;11. https://doi.org/10.3389/fnins.2017.00063.

145. Woldt $\mathrm{E}$, et al. Rev-erb-a modulates skeletal muscle oxidative capacity by regulating mitochondrial biogenesis and autophagy. Nat Med. 2013;19(8):1039-46. https://doi.org/10.1038/nm.3213.

146. Pircher $\mathrm{P}$, et al. Aberrant expression of myosin isoforms in skeletal muscles from mice lacking therev-erbAa orphan receptor gene. Am J Physiol Regul Integr Comparat Physiol. 2005;288(2):R482-90. https:// doi.org/10.1152/ajpregu.00690.2003.

147. Paganelli R, Petrarca C, Di Gioacchino M. Biological clocks: their relevance to immune-allergic diseases. Clin Mol Allergy. 2018;16(1). https://doi.org/10.1186/s12948-018-0080-0.

148. Lamia KA, et al. AMPK regulates the circadian clock by cryptochrome phosphorylation and degradation. Science. 2009;326(5951):437-40.

149. Bass J, Takahashi JS. Circadian integration of metabolism and energetics. Science. 2010;330(6009):1349-54. https://doi.org/10.1126/science. 1195027.

150. Gerhart-Hines Z, Lazar MA. Circadian metabolism in the light of evolution. Endocr Rev. 2015;36(3):289-304. https://doi.org/10.1210/er. 2015-1007.

151. Asher G, Schibler U. Crosstalk between components of circadian and metabolic cycles in mammals. Cell Metab. 2011;13(2):125-37. https:// doi.org/10.1016/j.cmet.2011.01.006.

152. Rutter J, Reick M, McKnight SL. Metabolism and the control of circadian rhythms. Annu Rev Biochem. 2002;71:307-31. https://doi.org/10.1146/ annurev.biochem.71.090501.142857.

153. Green CB, Takahashi JS, Bass J. The meter of metabolism. Cell. 2008;134(5):728-42. https://doi.org/10.1016/j.cell.2008.08.022.

154. Hironao K, Ashida H, Yamashita Y. The cacao procyanidin extract-caused anti-hyperglycemic effect was changed by the administration timings. JCBN. 2020;67(1):61-6. https://doi.org/10.3164/jcbn.20-45.

155. Dallmann $\mathrm{R}$, et al. The human circadian metabolome. Proc Natl Acad Sci. 2012;109(7):2625-9. https://doi.org/10.1073/pnas.1114410109.

156. Akhtar RA, et al. Circadian cycling of the mouse liver transcriptome, as revealed by CDNA microarray, is driven by the suprachiasmatic nucleus. Curr Biol. 2002;12(7):540-50. https://doi.org/10.1016/s0960-9822(02) 00759-5.

157. Mure LS, et al. Diurnal transcriptome atlas of a primate across major neural and peripheral tissues. Science. 2018;359(6381):eaao0318. https://doi.org/10.1126/science.aao0318.

158. Kita Y, et al. Implications of circadian gene expression in kidney, liver and the effects of fasting on pharmacogenomic studies. Pharmacogenetics. 2002;12(1):55-65. https://doi.org/10.1097/00008571-20020 1000-00008.

159. Zvonic S, et al. Characterization of peripheral circadian clocks in adipose tissues. Diabetes. 2006;55(4):962-70. https://doi.org/10.2337/diabetes. 55.04.06.db05-0873.

160. Davies SK, et al. Effect of sleep deprivation on the human metabolome. Proc Natl Acad Sci. 2014;111(29):10761-6. https://doi.org/10.1073/pnas. 1402663111.

161. Kim Y, et al. Mitochondria, metabolism, and redox mechanisms in psychiatric disorders. Antioxid Redox Signal. 2019;31(4):275-317. https:// doi.org/10.1089/ars.2018.7606.

162. Leproult R, Holmbäck U, Van Cauter E. Circadian misalignment augments markers of insulin resistance and inflammation, independently of sleep loss. Diabetes. 2014;63(6):1860-9. https://doi.org/10.2337/ db13-1546.

163. Arble DM, et al. Impact of sleep and circadian disruption on energy balance and diabetes: a summary of workshop discussions. Sleep (New York, NY). 2015;38(12):1849-60. https://doi.org/10.5665/sleep.5226.

164. Pastore N, Ballabio A. Keeping the autophagy tempo. Autophagy. 2019;15(10):1854-6. https://doi.org/10.1080/15548627.2019.1645545.

165. Kalsbeek A, la Fleur S, Fliers E. Circadian control of glucose metabolism. Mol Metab. 2014;3(4):372-83. https://doi.org/10.1016/j.molmet.2014.03. 002.

166. Tao H, et al. Inhibition of expression of the circadian clock gene Period causes metabolic abnormalities including repression of glycometabolism in Bombyx mori cells. Sci Rep. 2016;7:46258. https://doi.org/10. 1038/srep46258.

167. Florian CN, et al. PAX6 mutation alters circadian rhythm and $\beta$ cell function in mice without affecting glucose tolerance. Commun Biol. 2020;3(1):628-628. https://doi.org/10.1038/s42003-020-01337-x.

168. Lamia KA, Storch KF, Weitz CJ. Physiological significance of a peripheral tissue circadian clock. Proc Natl Acad Sci. 2008;105(39):15172-7. https:// doi.org/10.1073/pnas.0806717105.

169. Marcheva B, et al. Disruption of the clock components CLOCK and BMAL1 leads to hypoinsulinaemia and diabetes. Nature. 2010;466(7306):627-31. https://doi.org/10.1038/nature09253.

170. Kil IS, et al. Circadian oscillation of sulfiredoxin in the mitochondria. Mol Cell. 2015;59(4):651-63. https://doi.org/10.1016/j.molcel.2015.06.031.

171. Peek CB, et al. Circadian clock NAD+ cycle drives mitochondrial oxidative metabolism in mice. Science. 2013;342(6158):1243417-1243417. https://doi.org/10.1126/science.1243417.

172. Schmitt K, et al. Circadian control of DRP1 activity regulates mitochondrial dynamics and bioenergetics. Cell Metab. 2018;27(3):657-666.e5. https://doi.org/10.1016/j.cmet.2018.01.011.

173. Wilking $M$, et al. Circadian rhythm connections to oxidative stress: implications for human health. Antioxid Redox Signal. 2013;19(2):192-208. https://doi.org/10.1089/ars.2012.4889.

174. Ramsay AL et al. Modeling Snyder-Robinson syndrome in multipotent stromal cells reveals impaired mitochondrial function as a potential cause for deficient osteogenesis. Sci Rep. 2019;9(1).https://doi.org/10. 1038/s41598-019-51868-5.

175. Wada T, et al. Deletion of Bmal1 prevents diet-induced ectopic fat accumulation by controlling oxidative capacity in the skeletal muscle. Int J Mol Sci. 2018;19(9):2813. https://doi.org/10.3390/ijms19092813.

176. Yoo ID, et al. Elevated CLOCK and BMAL1 contribute to the impairment of aerobic glycolysis from astrocytes in Alzheimer's disease. Int J Mol Sci. 2020;21(21):7862. https://doi.org/10.3390/ijms21217862.

177. Amos D, Cook C, Santanam N. Omega 3 rich diet modulates energy metabolism via GPR120-Nrf2 crosstalk in a novel antioxidant mouse model. Biochim Biophys Acta (BBA) Mol Cell Biol Lipids. 2019;1864(4):466-88. https://doi.org/10.1016/j.bbalip.2019.01.002.

178. Depner CM, et al. Mistimed food intake and sleep alters 24-hour timeof-day patterns of the human plasma proteome. Proc Natl Acad Sci. 2018;115(23):E5390-9. https://doi.org/10.1073/pnas.1714813115.

179. Archer SN, et al. Mistimed sleep disrupts circadian regulation of the human transcriptome. Proc Natl Acad Sci. 2014;111(6):E682-91. https:// doi.org/10.1073/pnas.1316335111.

180. Roh $\mathrm{E}$, et al. Effects of chronic NAD supplementation on energy metabolism and diurnal rhythm in obese mice. Obesity (Silver Spring). 2018;26(9):1448-56. https://doi.org/10.1002/oby.22263.

181. Lowrey PL, Takahashi JS. Mammalian circadian biology: elucidating genome-wide levels of temporal organization. Annu Rev Genomics Hum Genet. 2004;5(1):407-41. https://doi.org/10.1146/annurev. genom.5.061903.175925.

182. Zheng Z, et al. CREBH couples circadian clock with hepatic lipid metabolism. Diabetes. 2016;65(11):3369-83. https://doi.org/10.2337/ db16-0298.

183. Goni L, et al. A circadian rhythm-related MTNR1B genetic variant modulates the effect of weight-loss diets on changes in adiposity and body composition: the POUNDS Lost trial. Eur J Nutr. 2019;58(4):1381-9. https://doi.org/10.1007/s00394-018-1660-y.

184. Summa KC, Turek FW. Chronobiology and obesity: interactions between circadian rhythms and energy regulation. Adv Nutr. 2014;5(3):312S-319S. https://doi.org/10.3945/an.113.005132. 
185. Boucsein A, Rizwan MZ, Tups A. Hypothalamic leptin sensitivity and health benefits of time-restricted feeding are dependent on the time of day in male mice. FASEB J. 2019;33(11):12175-87. https://doi.org/10. 1096/fj.201901004R.

186. Dalbram E, et al. Voluntary wheel running in the late dark phase ameliorates diet-induced obesity in mice without altering insulin action. J Appl Physiol. 2019;126(4):993-1005. https://doi.org/10.1152/japplphysi ol.00737.2018.

187. Cutolo M. Circadian rhythms and rheumatoid arthritis. Joint Bone Spine 2019;86(3):327-33. https://doi.org/10.1016/j.jbspin.2018.09.003.

188. Cutolo M, et al. Nocturnal hormones and clinical rhythms in rheumatoid arthritis. Annal NY Acad Sci. 2005;1051(1):372-81. https://doi.org/ 10.1196/annals.1361.079.

189. Cutolo M. Glucocorticoids and chronotherapy in rheumatoid arthritis. RMD Open. 2016;2(1): e000203. https://doi.org/10.1136/rmdop en-2015-000203.

190. Proctor CJ, Gartland A. Simulated interventions to ameliorate agerelated bone loss indicate the importance of timing. Front Endocrinol (Lausanne). 2016;7:61-61. https://doi.org/10.3389/fendo.2016.00061.

191. Rozner $\mathrm{R}$, et al. The role of Omega-3 polyunsaturated fatty acids from different sources in bone development. Nutrients. 2020;12(11):3494. https://doi.org/10.3390/nu12113494.
192. Wellen KE, et al. ATP-citrate lyase links cellular metabolism to histone acetylation. Science. 2009;324(5930):1076-80. https://doi.org/10.1126/ science.1164097.

193. Tsukada Y, et al. Histone demethylation by a family of JmjC domaincontaining proteins. Nature. 2006;439(7078):811-6. https://doi.org/10 1038/nature04433.

194. Tahiliani M, et al. Conversion of 5-methylcytosine to 5-hydroxymethylcytosine in mammalian DNA by MLL partner TET1. Science. 2009;324(5929):930-5. https://doi.org/10.1126/science.1170116.

195. Rodan GA, Rodan SB, Marks SC. Parathyroid hormone stimulation of adenylate cyclase activity and lactic acid accumulation in calvaria of 4 osteopetrotic (ia ) rats*. Endocrinology. 1978;102(5):1501-5. https://doi. org/10.1210/endo-102-5-1501.

196. Riddle RC, Clemens TL. Bone cell bioenergetics and skeletal energy homeostasis. Physiol Rev. 2017;97(2):667-98. https://doi.org/10.1152/ physrev.00022.2016.

\section{Publisher's Note}

Springer Nature remains neutral with regard to jurisdictional claims in published maps and institutional affiliations.
Ready to submit your research? Choose BMC and benefit from:

- fast, convenient online submission

- thorough peer review by experienced researchers in your field

- rapid publication on acceptance

- support for research data, including large and complex data types

- gold Open Access which fosters wider collaboration and increased citations

- maximum visibility for your research: over $100 \mathrm{M}$ website views per year

At BMC, research is always in progress.

Learn more biomedcentral.com/submissions 